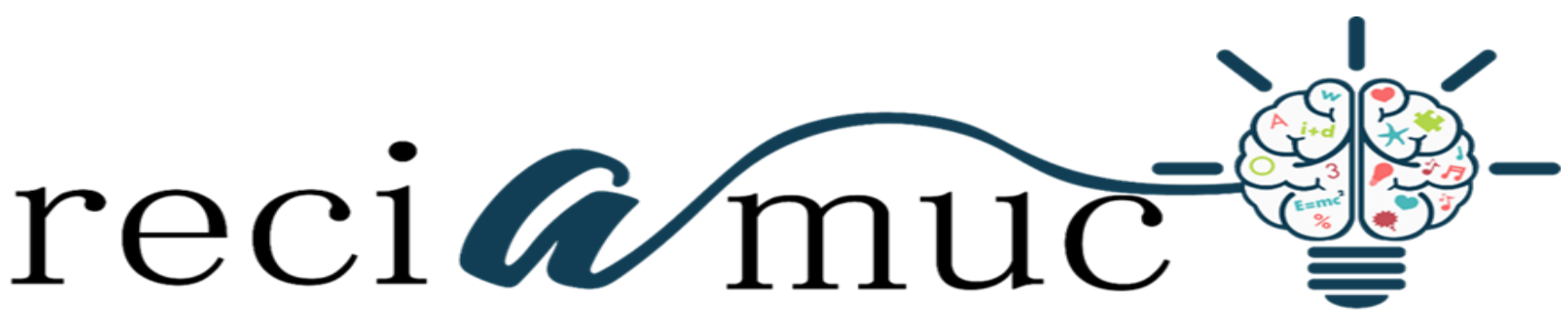

Revista cientifica de investigación actualización del mundo de las ciencias

Rubí Alisba Borja Torres ${ }^{\text {a; }}$ Katherine Elizabeth Mora Euvin ${ }^{\text {b; }}$ Giannella Lissette Ramírez López ${ }^{\text {c; }}$ Erika Claribel Albán Estrada ${ }^{d}$

Incidencia de la ruptura prematura de membrana en adolescentes embarazadas

Incidence of premature membrane rupture in pregnant adolescents

Revista Científica de Investigación actualización del mundo de las Ciencias. Vol. 3 núm., 1, enero, ISSN: 2588-0748, 2018, pp. 328-352

DOI: 10.26820/reciamuc/3.(1).enero.2019.328-352

URL: $\underline{\text { http://reciamuc.com/index.php/RECIAMUC/article/view/238 }}$

Código UNESCO: 3205 Medicina Interna

Tipo de Investigación: Artículo de Revisión

Editorial Saberes del Conocimiento

Recibido: 10/12/2018

Aceptado: 20/01/2019

Publicado: 30/01/2019

Correspondencia: director@ reciamuc.com

a. Médico; Guayaquil, Ecuador.
b. Médico; Guayaquil, Ecuador.
c. Médico; Guayaquil, Ecuador.
d. Médico; Guayaquil, Ecuador. 


\section{Incidencia de la ruptura prematura de membrana en adolescentes \\ embarazadas}

Vol. 3, núm. 1., (2019)

Rubí Alisba Borja Torres; Katherine Elizabeth Mora Euvin; Giannella Lissette Ramírez López;

Erika Claribel Albán Estrada

\section{RESUMEN}

Uno de los problemas de salud pública con mayor incidencia a nivel mundial, se basa en el incremento del embarazo en jóvenes que van desde los doce hasta los diecinueve años; esta condición, constituye una problemática social y de salud que afecta principalmente a adolescentes, las cuales producto a su desconocimiento y diversos factores no reciben el control médico adecuado durante su embarazo, lo que en consecuencia aumenta su riesgo a complicaciones médicas tales como, embarazos prematuros, enfermedades de tipo sexual, infecciones urinarias y ruptura prematura de membrana; esta última reconocida como una complicación obstétrica frecuente, que ocurre de hecho en un poco más del 10 por ciento de todos los embarazos y que es el antecedente previo de partos pretérmino, por lo menos en una de cada tres gestantes; asimismo, una de cada cinco RPM ocurre antes de las 37 semanas de gestación, la misma puede deberse a múltiples factores entre los que se pueden mencionar: el desconocimiento del funcionamiento de la sexualidad y anticoncepción, control del embarazo, el poco acceso a los servicios de atención a la salud (planificación familiar), la falta de comunicación y orientación de la escuela y familia sobre la sexualidad, la inestabilidad familiar, la actitud negativa de los padres ante la pareja y la actividad sexual, falta de afecto, confianza, comunicación, exceso de permisos, entre otras. En efecto, la RPM representa un problema clínico y epidemiológico. Dentro de las complicaciones fetales se describen principalmente Infección neonatal, prematurez, síndrome de dificultad respiratoria y depresión neonatal, que se pueden explicar por aumento en la incidencia de asfixia perinatal por infección fetal, prolapso de cordón, DPP, presentaciones distócicas y compresión funicular por oligoamnios; razones éstas que llevan a considerar la importancia del presente artículo, el cual tiene por propósito analizar la incidencia de la ruptura prematura de membrana en adolescentes.

Palabras Claves: Ruptura Prematura de Membrana; Embarazo en Adolescentes; Enfermedades Sexuales; Infecciones Urinarias; Complicaciones Médicas. 


\title{
Incidencia de la ruptura prematura de membrana en adolescentes embarazadas
}

Vol. 3, núm. 1., (2019)

Rubí Alisba Borja Torres; Katherine Elizabeth Mora Euvin; Giannella Lissette Ramírez López; Erika Claribel Albán Estrada

\begin{abstract}
One of the public health problems with greater incidence worldwide, is based on the increase in pregnancy in young people ranging from twelve to nineteen years; This condition is a social and health problem that mainly affects adolescents, which are ignored and various factors do not receive adequate medical control during their pregnancy, which consequently increases their risk of medical complications such as premature pregnancies, diseases of a sexual nature, urinary infections and premature membrane rupture; the latter is recognized as a frequent obstetric complication, which occurs in fact in a little more than 10 percent of all pregnancies and which is the previous antecedent of preterm births, in at least one out of every three pregnant women; also, one in five RPM occurs before 37 weeks of gestation, the same can be due to multiple factors among which can be mentioned: the ignorance of the functioning of sexuality and contraception, pregnancy control, poor access to services health care (family planning), lack of communication and orientation of the school and family about sexuality, family instability, negative attitude of the parents before the couple and sexual activity, lack of affection, trust, communication, excess of permits, among others. In effect, the MPR represents a clinical and epidemiological problem. Fetal complications include mainly neonatal infection, prematurity, respiratory distress syndrome and neonatal depression, which can be explained by an increase in the incidence of perinatal asphyxia due to fetal infection, cord prolapse, PPD, dystocic presentations and funicular compression by oligohydramnios; reasons that lead to consider the importance of this article, which aims to analyze the incidence of premature membrane rupture in adolescents.
\end{abstract}

Key Words: Premature Membrane Rupture; Pregnancy in Adolescents; Sexual diseases; Urinary infections; Medical complications. 


\section{Incidencia de la ruptura prematura de membrana en adolescentes \\ embarazadas}

Vol. 3, núm. 1., (2019)

Rubí Alisba Borja Torres; Katherine Elizabeth Mora Euvin; Giannella Lissette Ramírez López;

Erika Claribel Albán Estrada

\section{Introducción.}

Actualmente, se observa que el embarazo y la maternidad temprana han alcanzado grandes proporciones en todo el mundo. En base a esto, (OMS, 2017), expone "cada año nacen más de dos millones de niños en América Latina y el Caribe, el 80\% de estos ocurre entre adolescentes con edades comprendidas entre 14 y 19 años de edad". (p.12). Lo descrito permite entender que, cada vez son más las cifras que resaltan la complejidad que representa el embarazo a temprana edad, situación ésta que lleva a considerar que cada día son mayores los indicadores de la desorientación presente en los adolescentes en cuanto a las implicaciones y consecuencias médicas que puede ocasionar el hecho de asumir una relación sexual de manera irresponsable, en el caso de quedar embarazadas.

Para (Duarte, 2016) "las embarazadas a temprana edad desarrollan una serie de cambios biológicos y sociales, debido al hecho de que sus vidas, causándole riesgos a su vida, los cuales en consecuencia ocasionan un problema de salud pública". (p.15). En consecuencia, cuando se habla de problemas de salud pública, se debe hacer referencia a un conjunto de patologías y afecciones médicas que afectan a las comunidades, convirtiéndose en problemas sociales que traen consecuencias, no sólo a las familias, sino a las Naciones en general; destáquese entre éstas, el embarazo precoz, el cual ha ido en aumento en el mundo entero. Según datos devenidos de la (OPS, 2017):

Los aspectos relacionados con el embarazo en la adolescencia son alarmantes, ya que en América Latina y el Caribe, más de 100.000 niños nacen anualmente de madres con edades comprendidas entre quince y diecinueve años, una de cada cinco 


\section{Incidencia de la ruptura prematura de membrana en adolescentes embarazadas}

Vol. 3, núm. 1., (2019)

Rubí Alisba Borja Torres; Katherine Elizabeth Mora Euvin; Giannella Lissette Ramírez López; Erika Claribel Albán Estrada

mujeres adolescentes ha sido madre antes de los 20 años y una de cada tres

defunciones infantiles corresponde a hijos de madres adolescentes. (p.18).

Lo descrito anteriormente, lleva a considerar el embarazo precoz como una debilidad en el campo de la salud presente en la sociedad actual, la cual es demostrada en las cifras emanadas de instituciones médicas de gran valor, como lo es la (OMS 2017), la cual refiere que una de cada cinco mujeres han sido madres adolescentes. Por tal razón, se puede decir que este tipo de maternidad, es considerada como un problema social primario, caracterizado por las consecuencias observadas en los múltiples casos de morbilidad observados, en la ruptura prematura de membrana bajo peso al nacer presente en algunos de estos niños, en la prematurez y un alto riesgo de morbi-mortalidad materna, perinatal e infantil.

A raíz de lo expuesto, se puede considerar que el embarazo en la adolescencia constituye un problema de salud pública, no sólo por sus altas cifras, sino por los riesgos de salud que conlleva; obsérvese que la principal causa de muerte existente en las jóvenes que oscilan entre los trece y diecinueve años continúa siendo la obstétrica directa, así como las complicaciones del aborto, especialmente el inducido y el realizado en condiciones inseguras, conocido como aborto ilegal, el cual generalmente es desarrollado por estas jóvenes ante la inseguridad de enfrentarse a la sociedad y, sobre todo a la familia.

De más está decir, que las cifras antes mencionadas confirman la situación existencial de un número considerable de adolescentes que residen en países latinoamericanos, donde las mujeres jóvenes tienen relaciones sin tomar en cuenta la prevención, lo cual constituye un riesgo inminente, porque así como pueden quedar embarazadas por falta de cuidados anticonceptivos, 


\section{Incidencia de la ruptura prematura de membrana en adolescentes \\ embarazadas}

Vol. 3, núm. 1., (2019)

Rubí Alisba Borja Torres; Katherine Elizabeth Mora Euvin; Giannella Lissette Ramírez López;

Erika Claribel Albán Estrada

o, simplemente presentar una serie de complicaciones médicas, entre las que se pueden señalar, las que derivan de la ruptura temprana de membrana. En apoyo a esto, (Cambell, 2014), expone, "la ruptura prematura de membrana en adolescentes embarazadas representa un problema de salud pública de importancia clínica y epidemiológica a nivel mundial debido al alto riesgo de complicaciones materno perinatal". (p.112).

Entiéndase con esto que, la ruptura temprana de membrana RPM tiene importantes repercusiones en los resultados perinatales, ya que es la causa de más del $30 \%$ de los partos pretérminos, y por sus consecuencias y complicaciones la causa de un $10 \%$ de la mortalidad perinatal. En unión a esto, Cambell (Obcit) refiere, "esta patología se debe a la rotura de las membranas amnióticas antes del inicio del parto, independientemente de que se produzca antes de término, a término o después de término". (p.123).Por consiguiente, se debe comprender que la ruptura prematura de membranas es la pérdida de continuidad de las membranas corioamniótica y puede ocurrir en cualquier momento de la gestación, pero se asocia a mayor morbilidad cuando ocurre en el parto pretérmino, generalmente se presenta aproximadamente en un tercio de los partos prematuros.

En concordancia de estos planteamientos, autores como (Zulliett, 2014), afirman que la ruptura prematura de membrana se asocia de manera directa con:

La rotura estrechamente vinculada con la duración del periodo de latencia, cuando el mismo supera las 24 horas (rotura prolongada) el riesgo se prematura de las membranas ovulares aumenta la morbimortalidad materna a expensas de la infección. La frecuencia y gravedad de éstas se encuentra incrementa significativamente. (p.95). 


\section{Incidencia de la ruptura prematura de membrana en adolescentes embarazadas}

Vol. 3, núm. 1., (2019)

Rubí Alisba Borja Torres; Katherine Elizabeth Mora Euvin; Giannella Lissette Ramírez López; Erika Claribel Albán Estrada

Lo antes expuesto, conduce a resaltar que la ruptura prematura de membranas aumenta su morbimortalidad según su latencia, la cual se refiere al tiempo que transcurre entre la ruptura y la terminación del embarazo; lo que lleva a entender que, el periodo de latencia y la edad gestacional son los encargados de determinar el pronóstico y consecuentemente el manejo de la enfermedad de acuerdo a la posibilidad que se tenga de terminar felizmente esta etapa de gestación. En acompañamiento de esto, (Zurita, 2012):

La Ruptura prematura de membranas es un evento que se presenta con mucha frecuencia en enfermedades de transmisión sexual, en embarazos gemelares, en los polihidramnios, en las malformaciones uterinas, en los embarazos que transcurren junto con tumores uterinos; en situaciones de bajo nivel socio económico, bajo peso materno, parto prematuro previo, metrorragia del 2do y 3er trimestre.(p.16).

Lo descrito por la autora permite comprender que, entre otras cosas, la ruptura de las membranas cuando ocurre de manera temprana se encuentra asociada con infecciones del cuello de la matriz y de la vagina, con infecciones vaginales crónicas, con cistitis (infección de las vías urinarias) repetitivas y con anomalías de la situación del bebé. Así también, (Becerra, 2011)

Entre los factores que pueden estar vinculados con la ruptura prematura de membrana RPM se pueden incluir los siguientes: Condición socioeconómica baja (por la menor probabilidad de recibir cuidados médicos prenatales adecuados) Infecciones de transmisión sexual como por ejemplo, la clamidia y la gonorrea. Traumatismos, generalmente externos, que producen cambios bruscos de movimientos fetales $\mathrm{y}$ del útero mismo, aplastamiento, estiramientos o 


\section{Incidencia de la ruptura prematura de membrana en adolescentes \\ embarazadas}

Vol. 3, núm. 1., (2019)

Rubí Alisba Borja Torres; Katherine Elizabeth Mora Euvin; Giannella Lissette Ramírez López;

Erika Claribel Albán Estrada

modificaciones en su estructura. (caídas, estornudos fuertes, coito)Incompetencia ístmico cervical IIC, que se produce a partir de la semana 12.Deficiencia de vitamina C y cobre. Parto prematuro previo Hemorragia vaginal. El tabaquismo durante el embarazo. Causas desconocidas. (p.11).

Lo antes señalado, lleva a considerar que la ruptura prematura de membrana representa una patología que puede deberse a múltiples factores, los cuales en su mayoría se incrementan en las adolescentes; de allí, la importancia de que las mismas lleven un control prenatal, en el que se pueda detectar causas que puedan llevar a una RPM, tales como la presencia de secreciones vaginales (producidas por bacterias, hongos o parásitos), así como también infecciones a nivel de las vías urinarias, por ser éstas unas de las causantes de generar este problema de salud. Para (Guerrero, 2015):

Es necesario que las adolescentes embarazadas sigan un control prenatal, el cual le permita al médico tratante, identificar algún tipo de riesgo que pudiera generarles una RPM, tales como la presencia de infecciones vaginales, ante las que se debeimplementar un tratamiento precoz para evitar futurascomplicaciones, que en esencia representarían una emergencia obstétrica. (p.14).

En virtud de esto, es importante entender que toda adolescente embarazada debe, sin lugar a dudas, mantener un debido control prenatal, el cual permita brindarles a estas gestantes los cuidados obstétricos necesarios, para de esa forma, las mismas logren prevenir el alto índice de complicaciones e infecciones materno fetales existentes en la actualidad. Sin embargo, este planteamiento difiere de la realidad comprendida en un número considerable de embarazadas 


\section{Incidencia de la ruptura prematura de membrana en adolescentes embarazadas}

Vol. 3, núm. 1., (2019)

Rubí Alisba Borja Torres; Katherine Elizabeth Mora Euvin; Giannella Lissette Ramírez López; Erika Claribel Albán Estrada

adolescentes, las cuales, a consecuencia de múltiples factores desarrollan un embarazo sin ningún tipo de cuidado médico, que les permita identificar cualquier tipo de complicación médica que en su efecto pueda producir la ruptura prematura de membrana. Al respecto(Ferrer, 2016)

Se deben abordar varios tipos de estrategias para alcanzar la prevención del embarazo en las adolescentes, destáquese entre ellas, todas aquellas que estén implícitas en programas de atención primaria, entendidos éstos, como aquellos planes sociales o educativos encargados de fomentar o promover un estado óptimo de salud. (p.21).

La situación planteada exige la planificación de intervenciones que permitan enseñar hábitos y actitudes saludables para el cuidado y preservación del embarazo precoz. De allí, que es imperante fomentar entre jóvenes y estudiantes una cultura para la prevención de enfermedades y maternidades no deseadas, lo cual podría ser llevado a cabo, a través de políticas y programas, los cuales garanticen un aprendizaje eficiente y eficaz que redunden en beneficio de las estas poblaciones.

No obstante, lo antes señalado difiere de la realidad observada en un gran número de Naciones donde existe un elevado número de casos de niñas y jóvenes en edades entre los 12 y 19 años que asisten a los servicios de salud presentando como diagnóstico complicaciones propias de un embarazo no controlado; situación ésta que se aleja de los criterios mencionados anteriormente, lo que permite establecer la importancia del presente artículo, el cual, a través de 


\section{Incidencia de la ruptura prematura de membrana en adolescentes \\ embarazadas}

Vol. 3, núm. 1., (2019)

Rubí Alisba Borja Torres; Katherine Elizabeth Mora Euvin; Giannella Lissette Ramírez López;

Erika Claribel Albán Estrada

su desarrollo pretende analizar la incidencia de la ruptura prematura de membrana en adolescentes

\section{Método.}

Para el desarrollo de este proceso investigativo, se plantea como metodología la encaminada hacia una orientación científica particular que se encuentra determinada por la necesidad de indagar en forma precisa y coherente una situación, en tal sentido, Dávila (2012), define la metodología "como aquellos pasos previos que son seleccionados por el investigador para lograr resultados favorables que le ayuden a plantear nuevas ideas". (p53.)

Lo citado por el autor, lleva a entender que el desarrollo de la acción investigativa busca simplemente coordinar acciones enmarcadas en una revisión bibliográfica con el fin de complementar ideas previas relacionadas con: "La incidencia de ruptura prematura de membrana en adolescentes", para así finalmente elaborar un cuerpo de consideraciones generales que ayuden a ampliar el interés propuesto.

Tipo de Investigación

Dentro de toda práctica investigativa, se precisan acciones de carácter metodológico mediante las cuales, se logra conocer y proyectar los eventos posibles que la determinan, así como las características que hacen del acto científico un proceso interactivo ajustado a una realidad posible de ser interpretada. En este sentido, se puede decir, que la presente investigación corresponde al tipo documental, definido por (Dávila Obcit), "se ocupa del estudio de problemas 


\section{Incidencia de la ruptura prematura de membrana en adolescentes embarazadas}

Vol. 3, núm. 1., (2019)

Rubí Alisba Borja Torres; Katherine Elizabeth Mora Euvin; Giannella Lissette Ramírez López; Erika Claribel Albán Estrada

planteados a nivel teórico, la información requerida para abordarlos se encuentra básicamente en materiales impresos, audiovisuales y /o electrónicos”. (p.41).

En consideración a esta definición, la orientación metodológicapermitió la oportunidad de cumplir con una serie de actividades inherentes a la revisión y lectura de diversos documentos donde se encontraron ideas explicitas relacionadas con los tópicos encargados de identificar a cada característica insertada en el estudio. Por lo tanto, se realizaron continuas interpretaciones con el claro propósito de revisar aquellas apreciaciones o investigaciones propuestas por diferentes investigadores relacionadas con el tema de interés, para luego dar la respectiva argumentación a los planteamientos, en función a las necesidades encontradas en la indagación.

\section{Fuentes Documentales}

El análisis correspondiente a las características que predomina en el tema seleccionado, llevan a incluir diferentes fuentes documentales encargadas de darle el respectivo apoyo y en ese sentido cumplir con la valoración de los hechos a fin de generar nuevos criterios que sirven de referencia a otros procesos investigativos. Para (Arias, 2010), las fuentes documentales incorporadas en la investigación documental o bibliográfica, "representa la suma de materiales sistemáticos que son revisados en forma rigurosa y profunda para llegar a un análisis del fenómeno". (p.41). Por lo tanto, se procedió a cumplir con la realización de una lectura previa determinada por encontrar aquellos aspectos estrechamente vinculados con el tema, para luego explicar mediante un desarrollo las respectivas apreciaciones generales de importancia. 


\section{Incidencia de la ruptura prematura de membrana en adolescentes \\ embarazadas}

Vol. 3, núm. 1., (2019)

Rubí Alisba Borja Torres; Katherine Elizabeth Mora Euvin; Giannella Lissette Ramírez López;

Erika Claribel Albán Estrada

Técnicas para la Recolección de la Información

La conducción de la investigación para ser realizada en función a las particularidades que determinan a los estudios documentales, tiene como fin el desarrollo de un conjunto de acciones encargadas de llevar a la selección de técnicas estrechamente vinculadas con las características del estudio. En tal sentido, (Arias Obcit) refiere, que es "una técnica particular para aportar ayuda a los procedimientos de selección de las ideas primarias y secundarias". (p. 71).

Por ello, se procedió a la utilización del subrayado, resúmenes, fichaje, como parte básica para la revisión y selección de los documentos que presentan el contenido teórico. Es decir, que mediante su aplicación de estas técnicas se pudo llegar a recoger informaciones en cuanto a la revisión bibliográfica de los diversos elementos encargados de orientar el proceso de investigación. Tal como lo expresa, (Arias Obcit) "las técnicas documentales proporcionan las herramientas esenciales y determinantes para responder a los objetivos formulados y llegar a resultados efectivos" (p. 58). Es decir, para responder con eficiencia a las necesidades investigativas, se introdujeron como técnica de recolección el método inductivo, que hizo posible llevar a cabo una valoración de los hechos de forma particular para llegar a la explicación desde una visión general.

Asimismo, se emplearon las técnicas de análisis de información para la realización de la investigación que fue ejecutada bajo la dinámica de aplicar diversos elementos encargados de determinar el camino a recorrer por el estudio, según, (Arias, Obcit)las técnicas de procesamiento de datos en los estudios documentales "son las encargadas de ofrecer al investigador la visión o pasos que debe cumplir durante su ejercicio, cada una de ellas debe estar 


\section{Incidencia de la ruptura prematura de membrana en adolescentes embarazadas}

Vol. 3, núm. 1., (2019)

Rubí Alisba Borja Torres; Katherine Elizabeth Mora Euvin; Giannella Lissette Ramírez López; Erika Claribel Albán Estrada

en correspondencia con el nivel a emplear" (p. 123). Esto indica, que para llevar a cabo el procesamiento de los datos obtenidos una vez aplicado las técnicas seleccionadas, tales como: fichas de resumen, textual, registros descriptivos entre otros, los mismos se deben ajustar al nivel que ha sido seleccionado

\section{Resultados.}

\section{El Embarazo en Adolescentes}

El embarazo, representa una gestación que ocurre durante los dos primeros años ginecológicos de la mujer (edad ginecológica cero o edad de la menarquía) y/o cuando la adolescente mantiene la total dependencia social y económica de la familia parental. (Blanco 2008 p, 10). Según, la ((CEPAL), 2014):

Existe en la actualidad una incidencia cada vez mayor de casos de embarazos precoces, representados en el grupo etario entre 12 y 14 años, situación ésta que se le atribuye a la falta de educación sexual y desconocimiento sobre la sexualidad humana, lo cual trae como consecuencia infecciones de transmisión sexual, abortos, hijos no deseados, familias con sólo madre y un hijo, factores que en consecuencia se traducen en un problema para la sociedad. (p.28).

Se puede decir entonces que, el embarazo adolescente es más frecuente que lo que la sociedad quisiera aceptar; de allí, que entre sus posibles causas se encuentra el inicio temprano de la vida sexual de los jóvenes, el uso inadecuado o el no uso de métodos anticonceptivos, así como la falta o insuficiente información sobre sexualidad, el bajo nivel educativo y económico, 


\section{Incidencia de la ruptura prematura de membrana en adolescentes \\ embarazadas}

Vol. 3, núm. 1., (2019)

Rubí Alisba Borja Torres; Katherine Elizabeth Mora Euvin; Giannella Lissette Ramírez López;

Erika Claribel Albán Estrada

los bajos niveles de planeación y expectativas que poseen los jóvenes con respecto a su futuro, una pobre imagen y valorización de la mujer, sentimientos de soledad y rechazo, entre otras.

Ahora bien, es necesario mencionar que el problema del embarazo en la adolescencia tiene implicaciones importantes en la salud pública, siendo una preocupación tanto desde el punto de vista médico como psicosocial, ocurriendo con mayor frecuencia en adolescentes de medios socioeconómicos bajos, en familias desintegradas, numerosas o monoparenterales, afectadas por el desempleo, el cual es un fenómeno que se había presentado previamente en las propias madres de las adolescentes.

Entiéndase así, que el embarazo en la adolescente ha sido un fenómeno ampliamente estudiado desde la perspectiva de sus complicaciones médicas. Sin embargo, existen estudios que no han observado un incremento en la frecuencia de lamorbilidad y mortalidad materna y perinatal. Las condiciones al nacimiento del hijo de madre adolescente han sido reportadas como satisfactorias en relación a madres de 20 a 34 años.

Aunque no se encontraron en las adolescentes, mayores riesgos de salud materna y perinatal, no se eliminan las complicaciones sociales y psicológicas de tener un hijo en la adolescencia, ni la de otros riesgos a la salud como: la mayor mortalidad infantil en el primer año de vida y el riesgo de adquirir enfermedades de transmisión sexual. Para (Vielma, 2014):

Las principales causas de morbilidad durante el embarazo en la adolescencia son las infecciosas, incrementándose por ello, el nacimiento pretérmino y la ruptura de membranas, así como es más frecuente la preeclampsia y anemia. Se ha reportado el 


\section{Incidencia de la ruptura prematura de membrana en adolescentes embarazadas}

Vol. 3, núm. 1., (2019)

Rubí Alisba Borja Torres; Katherine Elizabeth Mora Euvin; Giannella Lissette Ramírez López; Erika Claribel Albán Estrada

incremento en el riesgo de presentar un parto pretérmino o muerte perinatal en embarazos en menores de 17 años, sin embargo este riesgo se reduce al controlar los efectos de las características económicas, ya que estos problemas se deben a la pobreza, nivel de escolaridad bajo, falta de recursos de atención para la salud y el rechazo de la sociedad.

Las situaciones antes descritas, permiten interpretar que el embarazo en adolescentes irrumpe en la vida de estas jóvenes en el momento, que las mismas todavía no alcanzan la madurez física y mental, a veces en circunstancias adversas, como lo son las carencias nutricionales $\mathrm{u}$ otras enfermedades $\mathrm{y}$ un medio familiar poco receptivo para aceptarlo $\mathrm{y}$ protegerlo; situaciones éstas que, llevan a considerar que el embarazo en esta etapa de la vida debe ser conceptualizado como un problema social de considerables consecuencias.

\section{Ruptura Temprana de Membranas (RPM)}

Actualmente, se observa que la ruptura prematura de membranas (RPM) ocurre en el 3\% de los embarazos y es responsable del 25 al 30\% de los nacimientos pretérmino, situación ésta que se presenta como un dilema para los obstetras y neonatólogos, quienes deben decidir entre continuar la gestación para disminuir la morbilidad relacionada con la prematurez o interrumpirla para prevenir los resultados adversos maternos y fetales relacionados con la ruptura prematura de membranas tales como corioamnionitis, abrupcio de placenta y compresión del cordón umbilical.

En otras palabras, es necesario entender que el riesgo de estas complicaciones se incrementa con la disminución de la edad gestacional a la cual ocurre la RPM, ya que en ellas se 


\section{Incidencia de la ruptura prematura de membrana en adolescentes \\ embarazadas}

Vol. 3, núm. 1., (2019)

Rubí Alisba Borja Torres; Katherine Elizabeth Mora Euvin; Giannella Lissette Ramírez López;

Erika Claribel Albán Estrada

observa de manera común que el intervalo entre la ruptura de membranas y el parto usualmente es corto, lo que lleva a la frecuencia y severidad de las complicaciones neonatales, las cuales después de la ruptura de las membranas varía y suceden, con incremento de éstas si se asocian además a infección, abrupcio de placenta o compresión del cordón umbilical u otras complicaciones serias que suelen presentarse como son: enterocolitis necrotizante, hemorragia intraventricular, y sepsis, las cuales son muy comunes en adolescentes.

En efecto, la ruptura prematura de membranas (RPM) representa un trastorno que se produce en el embarazo cuando el saco amniótico se rompe más de una hora antes del inicio del trabajo de parto. Una RPM se prolonga cuando se produce más de 18 horas antes del trabajo de parto. La ruptura de membranas es prematura cuando se produce antes del primer período del parto o período de dilatación. Ésta, suele ser causada por una infección bacteriana, por el tabaquismo o por un defecto en la estructura del saco amniótico, el útero o cérvix y también por las relaciones sexuales y la presencia de dispositivos Intrauterinos (DIU).

En algunos casos, la ruptura se puede curar espontáneamente, pero en la mayoría de los casos de RPM, el trabajo de parto comienza en las primeras 48 horas. Cuando esto ocurre, es necesario que la madre reciba tratamiento para evitar una posible infección en el recién nacido. Para (Daltón, 2014)

La ruptura prematura de membranas (RPM) es la pérdida de continuidad del saco amniótico antes del inicio del trabajo de parto, independientemente de la edad gestacional en que se encuentre el embarazo. Las membranas pueden romperse en cualquier momento del embarazo. Su incidencia varía entre el 1,6 y el $21 \%$ de todos 


\section{Incidencia de la ruptura prematura de membrana en adolescentes embarazadas}

Vol. 3, núm. 1., (2019)

Rubí Alisba Borja Torres; Katherine Elizabeth Mora Euvin; Giannella Lissette Ramírez López; Erika Claribel Albán Estrada

los nacimientos, y constituye una de las afecciones obstétricas más relacionadas con la morbilidad y mortalidad materno-perinatal. (p.25).

En base a lo señalado, se puede interpretar que la ruptura prematura de membrana representa en el embarazo de la adolescente un cuadro grave para el pronóstico perinatal, y su importancia está en relación inversa con la edad gestacional en que se produce, o sea, que mientras más temprano aparece, peores serán los resultados, pues constituye una de las afecciones obstétricas más relacionadas con la morbimortalidad materno perinatal.

\section{Su Etiología}

Se ha observado que la zona donde se produce la rotura de las membranas ovulares es pobre en colágeno III, está edematizada con depósito de material fibrinoide, un adelgazamiento en la capa trofoblástica y decidua. Bajo esas circunstancias de estimulación inmune, resulta que la elastasa de los granulocitos es específica para digerir ese tipo de colágeno, un cuadro característico en la corioamnitis.

Adicionalmente, las células deciduales, especialmente si hay bacterias, sintetizan prostaglandinas E2 y F2-alfa, que estimulan las contracciones uterinas, por lo que una combinación de corioamnitis e infección bacteriana son factores altamente predisponentes a una RPM.De igual forma, se ha encontrado asociación entre estados emocionales de miedo en una población y rotura prematura de membranas, ya que las mutaciones en los genes COL5A1, COL5A2, COL3A1, COL1A1, COL1A2, TNXB, PLOD1, ADAMTS2, CRTAP, LEPRE1 y ZMPSTE24 puede aumentar el riesgo de rotura prematura de membranas 


\section{Incidencia de la ruptura prematura de membrana en adolescentes \\ embarazadas}

Vol. 3, núm. 1., (2019)

Rubí Alisba Borja Torres; Katherine Elizabeth Mora Euvin; Giannella Lissette Ramírez López;

Erika Claribel Albán Estrada

\section{Diagnóstico}

La evaluación inicial de la rotura prematura de membranas en un feto pretérmino debe incluir un examen con espéculo estéril para documentar hallazgos sospechosos de la patología. También, es frecuente que se envien cultivos cervicales, incluyendo Chlamydia trachomatis y Neisseriagonorrhoeae, así como cultivos anovaginales para Streptococcusagalactiae. Con la ecografía se documenta la edad gestacional, peso fetal, presentación fetal y se establece el índice de líquido amniótico.

De igual manera, se puede realizar la determinación del $\mathrm{pH}$ vaginal con papel de tornasol o Nitracina, el que cambia de color ante la presencia de líquido amniótico. En estas pacientes se evita el tacto digital, pero la inspección visual del cuello uterino puede estimar con precisión la dilatación del mismo. Otras pruebas de diagnóstico son la prueba de Neuhaus y la de evaporizacion ante la sospecha de RPM. Por otra parte, se ha demostrado que el tacto manual y digital del cuello uterino con en pacientes con RPM reduce el período de latencia y aumenta el riesgo de infecciones, sin aportar información de verdadera utilidad clínica

\section{Complicaciones}

El riesgo principal de la ruptura de membranas es la infección en la mamá y en el bebé. Se considera que después de ocho horas de rotas las membranas la cavidad amniótica que 


\section{Incidencia de la ruptura prematura de membrana en adolescentes embarazadas}

Vol. 3, núm. 1., (2019)

Rubí Alisba Borja Torres; Katherine Elizabeth Mora Euvin; Giannella Lissette Ramírez López; Erika Claribel Albán Estrada

contiene al bebé tiene el potencial de estar ya infectada. Por supuesto, conforme el tiempo entre la ruptura y el nacimiento sea mayor, mayores serán las posibilidades de infección.Ahora bien, es necesario resaltar que la RPM es un factor que causa complicaciones en un tercio de los nacimientos prematuros, tales como:

\section{1.- Maternas:}

Como ya se ha mencionado, un riesgo importante es el desarrollo de una infección grave de los tejidos de la placenta, llamada "corioamnionitis", la cual puede resultar muy peligrosa para la madre y el bebé.

Infección puerperal

Es aquélla que se desarrolla en el tracto genital después del parto con fiebre de más de $38^{\circ} \mathrm{C}$.

Otras complicaciones incluyen

Desprendimiento de la placenta que estaba insertada normalmente (separación prematura de la placenta de la matriz), la compresión del cordón umbilical y prolapso del cordón (salida por vía vaginal antes de la cabeza del bebé).

\section{2.- Fetales:}

Antes del parto: 


\section{Incidencia de la ruptura prematura de membrana en adolescentes \\ embarazadas}

Vol. 3, núm. 1., (2019)

Rubí Alisba Borja Torres; Katherine Elizabeth Mora Euvin; Giannella Lissette Ramírez López;

Erika Claribel Albán Estrada

Sufrimiento fetal por falta de oxigenación cuando hay compresión del cordón umbilical o por falta de líquido amniótico.

Obitos

Falta de desarrollo de los pulmones del bebé (hipoplasia pulmonar) después del parto.

Síndrome de dificultad respiratoria (enfermedad de la membrana hialina)

Sepsis neonatal precoz: infección generalizada que ocurre durante las primeras 96 horas de vida. Es causado por microorganismos adquiridos "in útero" o durante el paso por el canal del parto.

Sindrome de respuesta inflamatoria sistémica

Prematurez. Muerte.

Fisiopatología de la Ruptura Prematura de Membrana

A) Aumento de la presión intraamniótica: la relación entre la presión intraamniótica y la tensión de las membranas viene definida por la ley de Laplace (figura), que indica que dicha tensión es proporcional a la presión intrauterina y al cuadrado del radio de la esfera $(\mathrm{T}=\mathrm{P} \times \mathrm{r} 2)$ por lo que pequeños aumentos del radio conducen a grandes incrementos de la tensión, que es probablemente el factor más importante para algunos autores en la RPM. 


\section{Incidencia de la ruptura prematura de membrana en adolescentes embarazadas}

Vol. 3, núm. 1., (2019)

Rubí Alisba Borja Torres; Katherine Elizabeth Mora Euvin; Giannella Lissette Ramírez López; Erika Claribel Albán Estrada

Esta tensión de la bolsa es habitualmente contenida y compensada por las paredes uterinas, excepto en el polo inferior del huevo a nivel de la dilatación del orificio cervical, por lo que es el radio de la dilatación el que fundamentalmente determinará los incrementos de tensión no compensados a nivel del orificio cervical, siendo este el punto habitual de rotura. Solo en caso de presiones intrauterinas muy elevadas, sin dilatación cervical, podría darse una rotura en puntos más altos.

B) Disminución de la resistencia de la bolsa amniótica: la bolsa de las aguas está constituida por 2 capas (el amnios y el corion), como ya se había señalado. Ambas capas están yuxtapuestas y presentan la capacidad de deslizamiento de una sobre otra. Esta estructura posee la capacidad de mantenerse íntegra hasta fases avanzadas del parto.10 La actividad de enzimas proteolíticas, colagenasas y elastasas debilitaría su resistencia y precipitaría la rotura de la misma. Esta actividad enzimática se vería condicionada por:

- Infecciones: las bacterias son capaces de desarrollar actividad proteolítica que destruye el colágeno, pudiendo además favorecer la colagenasa de los neutrófilos. Las infecciones pueden ocurrir por vía ascendente (vagina o cérvix) hacia decidua, corion, amnios, cavidad amniótica y feto, o por vía hematógena (peritoneal, amniocentesis, biopsia de vellosidades coriales, o traumatismos con ingreso a cavidad amniótica).

Cualquier germen puede provocar la infección, los más frecuentemente encontrados son: Ureaplasmaurealyticum, Fusobacteriumspecies, Mycoplasmaominis, Estreptococus grupo B, 


\section{Incidencia de la ruptura prematura de membrana en adolescentes \\ embarazadas}

Vol. 3, núm. 1., (2019)

Rubí Alisba Borja Torres; Katherine Elizabeth Mora Euvin; Giannella Lissette Ramírez López;

Erika Claribel Albán Estrada

Estreptococusviridans, Gardnerellavaginalis, entre otros. En los procesos infecciosos hay que considerar la fosfolipasa A2, la fosfolipasa C, y los lipopolisacáridos que estimulan la síntesis de prostaglandinas, las colagenasas bacterianas, las citoquinas, los macrófagos y granulocitos, así como la prostaglandina E2 con los consiguientes cambios cervicales e inicio de dinámica uterina, las interleucinas que activan la síntesis de prostaglandinas, y la apoptosis.

- Coito: en el coito existen sustancias que pueden conducir al mismo efecto. Las enzimas collagen-like y las prostaglandinas (que estimulan la proteolisis).

- Tabaquismo: en las fumadoras se produce una reacción pulmonar que aumenta la actividad proteolítica y disminuye la de los inhibidores proteolíticos.

- Aumento de la concentración de hexosamina en la capa mesenquimatosa del amnios.

- Déficit nutricionales y de oligoelementos: difícilmente demostrables.10 Pero la bolsa también sufre una serie de cambios estructurales que la debilitan a lo largo de la gestación, entre los cuales se da, incluso, una disminución de su contenido en colágeno, por lo que su rotura a término puede considerarse una variedad fisiológica por ese normal debilitamiento intrínseco.

C) Acciones traumáticas sobre la bolsa de las aguas: son difíciles de demostrar:

- Adherencias entre el corioamnios y decidua, lo que produciría un estiramiento corioamniótico al desplegarse el segmento uterino inferior, el crecimiento uterino y las contracciones. Esto incrementaría la tensión de la bolsa y facilitaría su rotura.

- Traumatismos externos (3\%): tacto vaginal, amnioscopia, etcétera. 


\section{Incidencia de la ruptura prematura de membrana en adolescentes embarazadas}

Vol. 3, núm. 1., (2019)

Rubí Alisba Borja Torres; Katherine Elizabeth Mora Euvin; Giannella Lissette Ramírez López; Erika Claribel Albán Estrada

- Traumatismos internos: movilidad del feto sobre el polo inferior ovular.

En consecuencia, lo antes señalado lleva a identificar un problema de salud pública de orden mundial, el cual pudiera deberse a múltiples factores, entre ellos, el bajo nivel socio económico de estas jóvenes y el desconocimiento que éstas tienen sobre los riesgos de salud que genera un embarazo a temprana edad, estableciéndose con esto, la necesidad de promover políticas de salud que logren minimizar esta situación, pues de mantenerse en el tiempo, se pudiera generar el aumento progresivo de este tipo de casos, y en consecuencia el aumento de la morbimortalidad generada a consecuencia de la ruptura prematura de membranas generadas mayormente, por la ausencia de un control preventivo del embarazo.

\section{Conclusiones.}

La ruptura prematura de membrana (RPM) se conceptualiza como la rotura de revestimientos ovulares posterior a las 21 semanas de edad gestacional hasta 1 hora antes del trabajo de parto. Cuando la RPM se produce antes de la semana 37 se le denomina ruptura prematura de membrana pretérmino (RPMP). Su importancia radica, en que está asociada a casos de parto pretérmino, conllevando a un elevado riesgo de morbilidad y mortalidad materna y neonatal constituyendo así un problema de salud pública.

La mayoría de los partos pretérminoestán relacionados con RPM, por lo que se considera un problema obstétrico importante, ya que el gran parte de la morbimortalidad fetal es consecuencia de la prematurez. Hoy en día, un neonato pretérmino debido a la ruptura prematura de membrana se está convirtiendo en un problema de salud pública, pues es el comienzo de 


\section{Incidencia de la ruptura prematura de membrana en adolescentes \\ embarazadas}

Vol. 3, núm. 1., (2019)

Rubí Alisba Borja Torres; Katherine Elizabeth Mora Euvin; Giannella Lissette Ramírez López;

Erika Claribel Albán Estrada

innumerables dificultades que tendrá que atravesar el recién nacido y su madre para lograr un estado físico y psicológico adecuados, implicando además una inversión económica, social y emocional para la familia de los expuestos.

La rotura prematura de membrana (RPM) actualmente representa una de las principales razones de morbilidad infecciosa en el neonato y la madre. Al mismo tiempo es un proceso de causas multifactoriales como factores clínicos, epidemiológicos y nutricionales.Los factores asociados a la ruptura prematura de membranas se han estudiado desde tiempo atrás, pero aún no se conoce con exactitud cuál es la causa de esta complicación obstétrica, se dice que es multifactorial y varía con la edad gestacional. A medida que la ruptura prematura de membrana ocurre a menor edad gestacional, se observa una mayor asociación con la infección del corion/decidua, aunque en algunos casos es difícil saber si la infección es la causa o es secundaria a la ruptura de las membranas.

En definitiva, la RPM es una patología que afecta en mayor grado a niñas y adolescentes en edades comprendidas entre los 12 y 19 años; puede producirse por una variedad de razones. Los mecanismos suelen ser diferentes según se trate de gestaciones de término o de pretérmino. En los embarazos a término puede ser el resultado de un debilitamiento fisiológico y normal, con procesos de degradación de la capa de colágeno de las membranas corioamnióticas, en combinación con fuerzas de estiramiento generadas por las contracciones. La RPM pretérmino puede ser el resultado de una amplia variedad de mecanismos patológicos que actúan individualmente o en conjunto. Ha quedado demostrada la asociación entre infección intraamniótica y RPM pretérmino, especialmente en edades gestacionales tempranas. 


\section{Incidencia de la ruptura prematura de membrana en adolescentes embarazadas}

Vol. 3, núm. 1., (2019)

Rubí Alisba Borja Torres; Katherine Elizabeth Mora Euvin; Giannella Lissette Ramírez López; Erika Claribel Albán Estrada

\section{Bibliografía.}

(CEPAL), C. E. (2014). Embarazo Precoz. Revista de Salud de Universidad Central de Venezuela UCV, Caracas, Venezuelal , 28.

Arias, F. (2010). Paradigmas de la Investigación Científica. España: Editorial: Luces.

Becerra, H. (2011). Complicaciones de un embarazo Precoz. Investigación clínica Aleatorizada.de la Escuela de Medicina de la Universidad Autónoma de México, 11.

Cambell, U. (2014). Ruptura Prematura de Membrana RPM. Colombia: Editorial: Bárcenas.

Daltón, S. (2014). La Ruptura Prematura de Membrana una complicación Médica en Embarazos. Revista de Salud Pública en México, 25.

Duarte, B. у. (2016). Complicaciones en embarazos no Deseados. Revista Medica Postgrado Instituto Hondureño de Seguridad UNAH, 15.

Ferrer, C. (2016). Medidas preventivas prara embarazo no deseados en Poblaciones Adolescentes. 2da edición, Médica Panamericana, 21.

Guerrero, P. (2015). Control Prenatal en Adolescentes. Revista Médica de la Universidad de Zulia LUZ en Maracaibo Venezuela, 14.

OMS, O. M. (2017). Factores asociados con la Ruptura Prematura de Membrana. Artículo de Salud de la Universidad de la Habana Cuba, 12.

OPS, O. P. (2017). El embarazo en adolescentes y sus complicaciones Médicas. Revista Salud y Enfermedad de la Escuela de Medicina de la Universidad de Los Andes ULA, en Mérida Venezuela, 18.

Vielma, R. (2014). Mortalidad en embarazos de Adolescentes. España: Editorial: Mediterráneo.

Zulliett, D. (2014). Complicaciones médicas asociadas a la Ruptura Prematura de Membrana. Colombia: Editorial: Nuevas Fuentes.

Zurita, E. (2012). Factores de Riesgo en embarazo de Adolescentes. Revista médica de Salud Actual de Santiago de Chile, 16. 